\title{
LAQUEADURA TUBÁRIA COMO CAUSA DE INFERTILIDADE - AVALIAÇÃO EM UM HOSPITAL UNIVERSITÁRIO
}

\author{
TUBAL STERILIZATION AS AN INFERTILITY CAUSE - AN \\ EVALUATION IN AN ACADEMIC HOSPITAL
}

DOI: $10.5380 /$ rmu.v1i2.40703

Francisco Beraldi de Magalhães ${ }^{1}$, Gleyse Maria Rubio Oliveira ${ }^{1}$, Leonardo Yoshida Osaku¹ ${ }^{1}$ Rosíres Pereira de Andrade ${ }^{1}$

\section{RESUMO}

Introdução: A laqueadura tubária é um método definitivo de contracepção, utilizado por um quarto das mulheres brasileiras. Nos ambulatórios de infertilidade conjugal com certa frequência, são atendidas pacientes que solicitam a reversão cirúrgica da laqueadura, por diferentes razões. Objetivo: Avaliar a prevalência de consultas por essa causa, as características sóciodemográficas dessas mulheres e as razões que as levam a pedir reversão do procedimento. Métodos: Estudo retrospectivo analisando os prontuários médicos das mulheres que consultaram nos últimos cinco anos no ambulatório de anticoncepção/infertilidade do Hospital de Clínicas. Resultados: Foram analisados 2.767 prontuários. Destes, 237 pacientes (8,5\%) consultaram por infertilidade, sendo 30 pacientes $(12,66 \%)$ com pedido de reversão da laqueadura tubária. A média de idade era de 33,8 anos, enquanto a de seus parceiros era de 34 anos. Possuíam filhos em uniões anteriores $90 \%$ das mulheres. $56 \%$ dos filhos eram criados pela própria paciente e o restante dividia-se entre guarda compartilhada, isolada do ex-parceiro ou de parentes da paciente. Com relação ao parceiro, $30,4 \%$ possuíam filhos em outras uniões, sendo que em todos os casos os filhos eram criados pela ex-parceira. Os principais motivos para desejar a reversão do procedimento foram arrependimento e desejo de mais filhos (96,1\%) e o parceiro desejar ter filhos $(76,9 \%)$. Conclusão: Pela possibilidade de separação e de novos relacionamentos, além do arrependimento, sugere-se que em mulheres com até 30 anos de idade a orientação deva ser direcionada para métodos contraceptivos reversíveis.

Palavras-chave: Esterilização tubária; reversão da esterilização; anticoncepção, tubas uterinas/cirurgia, infertilidade.

\section{ABSTRACT}

Introduction: The tubal sterilization is a surgical and definitive method to prevent pregnancy, used by a quarter of Brazilian women. However, in infertility clinics there are some patients requesting the sterilization reversal for different reasons. Objective: To evaluate the prevalence of medical appointments for this cause, the social-demographic characteristics of these women and the reason why they asked for the reversal. Methods: A retrospective study analyzing the medical records of the women who had an appointment in the last five years at the contraception/infertility clinic at Hospital de Clínicas. Results: 2767 medical records were analyzed. In 237 cases (8.5\%) the appointment reason was infertility and in 30 of them (12.66\%) was a request for a sterilization reversal. The women's average was 33.8 years, while, their partner's was 34 years. $90 \%$ of the women had children in previous relationships. $56 \%$ of them were brought up by her and the others were divided between shared care, just by the ex-husband or by patient's relatives. $30.4 \%$ of the women's partners had children in others relationships. In all cases, they were brought up by their expartners. The main reasons for reversal were their regret and the desire of having more children (96.1\%) and the partner's desire of having a child (76.9\%). Conclusion: Considering the possibilities of changes in the relationships and the future regretting, it is suggested that in women with at least 30 years, the contraceptive orientations should be directed for the reversible methods.

Key Words: Tubal sterilization; sterilization reversal; anticonception; Fallopian tubes/surgery; infertility.

1 - Universidade Federal do Paraná - UFPR

Contato do Autor / Mail to:

Francisco Beraldi de Magalhães - franbmagalhaes@uol.com.br

Rua General Carneiro, 181 - Alto da Glória, Curitiba - PR, 80060-900, 3o Andar, Serviço de Infectologia-HC/UFPR 


\section{REVISTA MÉDICA DO HC-UFPR}

\section{INTRODUÇÃO}

Planejamento familiar significa poder escolher o momento e o número de filhos que se deseja e envolve interesses pessoais e familiares assim como fatores socioeconômicos e o acesso a métodos contraceptivos testados cientificamente (1). Atualmente $80 \%$ das mulheres unidas utilizam algum tipo de método anticoncepcional, sendo que dentre todas as mulheres, $22,1 \%$ utilizam a pílula e $21,8 \%$ a esterilização feminina que consiste em um método cirúrgico, definitivo, para evitar a gravidez(2). Consiste na criação de uma barreira mecânica nas trompas uterinas através de secção, clipagem, eletrocoagulação ou ligadura por anel de Falópio(3). O percentual de mulheres que fizeram esterilização feminina é bem baixo nas primeiras idades, mas cresce acentuadamente a partir dos 25 anos, de tal forma que cerca de $40 \%$ das mulheres de $35-39$ anos e $51 \%$ das unidas de 45-49 anos encontram-se esterilizadas(2).

A reversão da laqueadura tubária é um processo caro e nem sempre bem sucedido. Portanto, é importante evitar ao máximo os pedidos de laqueadura tubária e para isso precisamos entender os fatores presentes no momento do pedido de esterilização que possam estar associados com 0 arrependimento(4). As taxas de reversões com nascidos vivos giram em torno de $30 \%$ a $48 \%$ das mulheres submetidas a laqueadura tubária. Um estudo de acompanhamento de 226 mulheres durante dois anos após cirurgia de reanastomose tubária revelou $63 \%$ de gestações. Entretanto, muitas mulheres que procuram os serviços de esterilidade desistem ou não conseguem realizar a cirurgia de reversão, e ainda, muitas das que são submetidas ao procedimento não conseguem uma gestação a termo(5).

Esse estudo tem a intenção de Identificar a prevalência de pedidos de reversão de laqueadura tubária no serviço de Reprodução Humana do Hospital de Clínicas da Universidade Federal do Paraná, traçando o perfil sócio-econômico dessas mulheres e definindo as razões que levaram a esse pedido.

\section{OBJETIVOS}

Objetivo Geral: Identificar as mulheres que consultaram no ambulatório de reprodução humana desejosas de reversão de laqueadura tubária prévia entre 01 de janeiro de 2004 e 30 de junho de 2009.

Objetivos específicos:

1. Pesquisar as características sóciodemográficas das mulheres com laqueadura tubária desejosas de reversão do procedimento.

2. Identificar o tempo decorrido desde a laqueadura realizada nessas mulheres até o pedido de reversão.
3. Estudar a idade dessas mulheres no momento em que foram submetidas à esterilização e a idade atual.

4. Avaliar o motivo que levou essas mulheres a pedir reversão da esterilização e o motivo do desejo de engravidar.

5. Identificar a via de acesso utilizada para a esterilização.

\section{REVISÃO DE LITERATURA}

A esterilização definitiva é um método anticoncepcional muito procurado, sendo que a laqueadura tubária é o mais usado em todo o mundo. Este método tem como mecanismo de ação a obstrução do lúmen tubário impedindo a migração dos espermatozóides em direção ao óvulo, fazendo com que a fecundação não ocorra, sem qualquer ação sobre hormônios. Os métodos usados podem ser: secção, clipagem, eletrocoagulação ou ligadura por anel de Falópio. Apesar de apresentar uma eficácia teórica de $100 \%$, o resultado obtido é de aproximadamente 0,3 casos de gravidez a cada 100 mulheres por ano(3).

A esterilização feminina é regulamentada pela Lei $n$ o 9.263, de 12 de janeiro de 1996, regula o $\S 70$ do art. 226 da Constituição Federal, que trata do planejamento familiar em seus princípios gerais(6). De acordo essa lei, é permitido esterilização em mulheres ou homens com capacidade civil plena e maiores de 25 anos ou pelo menos, com dois filhos vivos, desde que observado o prazo mínimo de 60 dias entre a manifestação da vontade e o ato cirúrgico, período no qual será propiciada a pessoa interessada acesso a serviço de regulação de fecundidade, incluindo aconselhamento por equipe multidisciplinar, visando desencorajar a esterilização precoce. Também é regulamentada no momento do parto somente na seguinte situação: "É vedada a esterilização cirúrgica em mulher durante período de parto, aborto ou até o 42 dia do pós-parto ou aborto, exceto nos casos de comprovada necessidade, por cesarianas sucessivas anteriores, ou quando a mulher for portadora de doença de base e a exposição a segundo ato cirúrgico ou anestésico representar maior risco para sua saúde. Neste caso, a indicação deverá ser testemunhada em relatório escrito e assinado por dois médicos"

Para traçar o perfil das mulheres que escolheram a laqueadura tubária como método contraceptivo, foi utilizado como apoio a Pesquisa Nacional de Demografia e Saúde da Criança e da Mulher (PNDS) realizada pelo Ministério da Saúde(2). Tal inquérito domiciliar nacional teve uma abrangência de 15.000 mulheres de 15 a 49 anos de idade e aproximadamente 6.000 crianças menores de 5 anos, representativo das cinco macrorregiões e dos contextos urbano e rural. Esta ampla pesquisa teve por 
objetivos principais caracterizar a população feminina em idade fértil e as crianças menores de 5 anos segundo fatores demográficos, socioeconômicos e culturais. Diversas características como padrões de conjugalidade, parentalidade, reprodutivos, morbimortalidade na infância, perfil de amamentação foram pesquisados, porém, o objeto de maior interesse para a atual pesquisa foi o capítulo sobre anticoncepção. Um fato pesquisado de grande relevância é o de que quase a totalidade das mulheres $(99,9 \%)$ conhece algum método contraceptivo. A esterilização feminina é o quarto método mais conhecido $(93,8 \%)$, perdendo apenas para métodos mais modernos e mais divulgados como a camisinha masculina $(99,8 \%)$, as pílulas anticoncepcionais (99,6\%), e a injeção contraceptiva (95,7\%). Outro dado que chama a atenção é que $21,8 \%$ de todas as mulheres, $29,1 \%$ das mulheres atualmente unidas e $10,8 \%$ das sexualmente ativas não unidas, recorreram à esterilização feminina como método anticoncepcional em algum momento da vida. Quando estratificamos estes dados por grupo etário, percebe-se um dado interessante. Dentre as mulheres entre 25 e 29 anos, $12,4 \%$ já realizaram a esterilização tubária, ou seja, mulheres que estão no grau máximo de fertilidade e recorreram a um método definitivo de anticoncepção. Tal fato é corroborado, quando se analisa a distribuição das mulheres esterilizadas segundo a idade no momento da esterilização e número de anos transcorridos desde a esterilização. Percebe-se que $63,4 \%$ de todas as cirurgias de laqueadura foram realizadas em mulheres de até 30 anos. Ainda com relação ao momento da realização de cirurgia, pode-se perceber que em $68,7 \%$ dos casos a laqueadura tubária foi realizada na ocasião do nascimento do ultimo filho. A influência de fatores sociodemográficos - número de filhos, anos de estudo, área de residência, região do país e cor da pele - é evidente. Ela mostra que a prevalência da esterilização cresce de forma acentuada com o número de filhos vivos: mais de $20 \%$ das mulheres com até dois filhos já se encontram esterilizadas e, entre as mulheres com 3 a 4 filhos, esse percentual alcança $62 \%$. O percentual de mulheres esterilizadas no grupo sem instrução é mais do que o dobro do percentual registrado no grupo de mulheres com nove e mais anos de estudo, o mesmo ocorrendo nas regiões Norte e Nordeste em relação ao Sul e ao Sudeste. Nas áreas rurais, e entre mulheres negras, a participação da esterilização é também muito maior do que a que se verifica nas áreas urbanas e entre mulheres brancas. Também são considerados fatores de risco para a laqueadura tubária, o estado marital com companheiro e o número de nascidos vivos sendo maior que o numero ideal de filhos.

A busca pela reversão da laqueadura tubária vem crescendo ao longo do tempo, porém sendo este método definitivo, os índices de sucesso são considerados baixos. A mulher que busca este método não deve ter dúvidas quanto ao desejo de sua realização e deve conhecer o procedimento.

Ao analisarmos as características sóciodemográficas, iniciando pelo fator idade do arrependimento, veremos que em um estudo casocontrole produzido em 2006 na cidade de Campinas SP identificou que a maioria das mulheres que se declararam arrependidas por terem realizado a esterilização apresentava idade inferior a 35 anos no momento da entrevista totalizando $59,6 \%$ da amostra(7). Em outro estudo caso-controle realizado em Recife no ano de 2005, indica que mulheres submetidas a esterilização com menos de 30 anos de idade, nos anos de 1980, em que a decisão foi tomada se baseando em alguma outra pessoa, que a cirurgia foi feita até o 45으 dia pós parto, sem receber informações suficientes sobre o procedimento e que adquiriram conhecimento após a esterilização apresentam um maior risco de arrependimento(1). Em um estudo prospectico produzido em Brasília no ano de 2007 foi encontrado como mediana a idade de 33 anos e 3 meses e como moda a faixa de idade entre 31 e 35 anos(8). Em um coorte retrospectivo realizado em Campinas mostrando que $46,9 \%$ das mulheres tinham entre 31 e 35 anos ao solicitarem a reversão(5). Já ao enfocarmos o número de filhos no momento da esterilização veremos que em um estudo caso-controle produzido em Campinas no ano de 1996, a chance de solicitar a reversão aumenta com o menor número de filhos(4). Podemos ainda somar a esse caso-controle, um segundo feito em 2006 que concluiu que mais de metade das mulheres que se declararam arrependidas da laqueadura tubária possuía até dois filhos, 84,4\% não pretendiam ter mais filhos. Este estudo também demonstra que mulheres esterilizadas antes de atingirem o número ideal de filhos têm mais chance de arrependimento do que aquelas que já o atingiram(7). Outro autor complementa que quanto ao número de filhos vivos das mulheres laqueadas por ocasião da primeira consulta, observou-se que $41,9 \%$ tinham dois filhos e $30,6 \%$ tinham três filhos(8). Analisando os parceiros que tinham filhos em outras uniões observase que há um excesso de mulheres que solicitam reversão quando o marido não tem filhos do casamento anterior é significante somente em mulheres que experimentaram a morte de um filho(1). Outro autor afirma que $87,8 \%$ dos parceiros atuais de mulheres desejosas de reversão não tinham filhos de relacionamentos anteriores(8).

Ao pesquisarmos a idade da realização da laqueadura, a literatura mostra que a maioria das mulheres foi submetida ao procedimento com idade entre 20 e 25 anos $(5 ; 8)$. Quanto ao intervalo de tempo decorrido entre a laqueadura tubária e a manifestação de arrependimento, observamos que: $43,9 \%$ das pacientes arrependem-se entre dois e quatro anos, 
$34,7 \%$ entre quatro e seis anos e $21,4 \%$ levam mais de seis anos para solicitar a reversão(8). Outro estudo em 1996 mostra que a maioria das mulheres $(46,3 \%)$ se arrepende após 7 a 11 anos da realização da laqueadura, enquanto $27,8 \%$ se arrepende após 1 a 6 $\operatorname{anos}(4)$.

Já ao estudarmos a idade da mulher desejosa de reversão no momento da laqueadura, nota-se que, $68,8 \%$ das mulheres tinham até 30 anos(7) dado que corrobora com outro estudo, que mostra a idade menor que 30 anos como fator de risco para o arrependimento(1). Já em 2007 foi afirmado que, a média de idade era de 24 anos e 6 meses(8).

Quanto ao motivo do pedido de reversão, as mulheres que trocam de parceiro têm uma chance quarenta vezes maior de solicitar reversão quando comparadas àquelas que não trocam(1). Um segundo autor também afirma que um novo matrimônio ou relacionamento apresentou freqüência de $80,6 \%$ dos casos, e acrescentou o crescimento dos filhos em $8,2 \%$ e morte dos filhos em $5,1 \%$ como motivo do desejo de reversão nas pacientes investigadas(8).

No que tange a identificação da via de acesso, observamos que no ano de 2006 em Campinas - SP um estudo mostra que quase $80 \%$ foram laqueadas durante uma cesariana(7). Outro autor expõe que o antecedente de pelo menos uma cesárea anterior ocorreu em $64,2 \%$ da amostra. Por outro lado, o último parto havia sido por meio de cesárea em $61,2 \%$ das mulheres. Acrescenta ainda que $73,1 \%$ foram submetidas a laqueadura intraparto e 26,9\% a laqueadura de intervalo(5).

\section{MÉTODOS}

Este é um estudo retrospectivo, descritivo realizado em hospital universitário. Foram analisados 2.767 prontuários de pacientes que consultaram no Ambulatório de Reprodução Humana do Hospital de Clínicas da Universidade Federal do Paraná entre 01 de janeiro de 2004 e 30 de junho de 2009. Os dados obtidos foram inseridos em uma ficha pré codificada com o intuito de responder os objetivos do estudo (Anexo I). Os resultados obtidos no estudo foram expressos por médias (variáveis quantitativas) ou por freqüências e percentuais (variáveis qualitativas). As comparações efetuadas foram realizadas pelo teste $t$ de Student para amostras pareadas. Valores de $p<0,05$ indicaram significância estatística. Os dados foram organizados em planilha Excel e analisados com o programa computacional Statistica v.8.0. Com relação à laqueadura tubária previamente realizada, foi questionado: há quanto tempo essa laqueadura havia sido realizada e qual a idade da paciente no momento da realização. Para abordarmos o por que do desejo da reversão, foram estabelecidos os seguintes motivos: 1- arrependimento, quer mais filhos; 2-tem um novo parceiro que deseja filhos; 3-falecimento de filhos; 4tem um novo parceiro e acha que um filho dele iria manter mais seguro o relacionamento; 5 -tem um novo parceiro e ele não está ciente da laqueadura; 6-quer mais um filho para ter companhia; 7-deseja reversão mas não tem argumentos; 8-por influência da televisão ou outros meios de comunicação; 9-não sabia que tinha sido esterilizada; 10-outros. Lembrando que a mulher poderia escolher mais de um dos motivos apresentados. Com relação ao motivo do desejo de engravidar estavam estimulados os seguintes itens nos prontuários: 1-quer um filho ou mais um filho-desejo de ser mãe; 2-tem novo parceiro que deseja filhos; 3falecimento de filhos; 4-tem um novo parceiro e acha que um filho dele iria manter mais seguro o relacionamento; 5-quer mais um filho para ter companhia; 6-parceiro ameaça separar-se caso não engravide; 7-o desejo de gestação é só da mulher; 8-0 desejo de gestação é só do parceiro; 9-o desejo de gestação é por pressão de familiares; 10 -outros. Nesse caso, a mulher também poderia escolher mais de um dos motivos selecionados.

Todas as mulheres assinaram a um Termo de Consentimento Livre e Esclarecido (Anexo II) por ocasião da consulta, onde se especificava o uso de dados para pesquisa científica. Este estudo foi aprovado pelo Comitê de Ética em Pesquisa em Seres Humanos do Hospital de Clínicas da Universidade Federal do Paraná. Este estudo foi realizado respeitando as boas práticas clínicas em pesquisa e obedeceu aos critérios estabelecidos pela Declaração de Helsinki da Associação Médica Mundial.

\section{RESULTADOS}

Dentre os 2.767 prontuários analisados, foram encontrados 237 pacientes que consultaram nesse ambulatório por infertilidade sendo 30 pacientes $(12,66 \%)$ com pedido de reversão de laqueadura tubária.

Essas mulheres possuem entre 24 e 42 anos de idade com uma média de 33,8 anos, sendo que $40,0 \%$ das mulheres possuem de 34 a 39 anos, $36,7 \%$ de 30 a 34 anos, $13,3 \%$ de 25 a 29 anos, $6,7 \% 40$ anos ou mais e $3,3 \%$ entre 20 e 24 anos. Seus parceiros possuem de 21 a 47 anos, sendo que $34,8 \%$ tem de 34 a 39 anos, $21,8 \%$ entre 30 e 34 anos, $17,4 \% 40$ anos ou mais, $13 \%$ tem de 25 a 29 anos e $13 \%$ de 20 a 24 anos. A média de idade dos parceiros foi de 34 anos(Tabela 1). Testou-se a hipótese nula de que a idade média da mulher que reverte a esterilização é igual a idade média do parceiro versus a hipótese alternativa de médias diferentes. $O$ resultado do teste estatístico indicou a não rejeição da hipótese nula no nível de significância de $5 \%(p=0,979)$ 


\section{ARTIGO ORIGINAL}

Tabela 1- Idade da Mulher e do Parceiro Por Ocasião da Primeira Consulta

\begin{tabular}{lcccc}
\hline & \multicolumn{3}{c}{ Mulher } & \multicolumn{2}{c}{ Homem } \\
\cline { 2 - 5 } & $\mathbf{n}$ & $\%$ & $\mathbf{n}$ & \% \\
$\mathbf{2 0}$ a $\mathbf{4}$ anos & 1 & $3,3 \%$ & 3 & $13,0 \%$ \\
$\mathbf{2 5}$ a $\mathbf{2 9}$ anos & 4 & $13,3 \%$ & 3 & $13,0 \%$ \\
$\mathbf{3 0} \mathbf{3 4}$ anos & 11 & $36,7 \%$ & 5 & $21,8 \%$ \\
$\mathbf{3 4}$ a 39 anos & 12 & $40,0 \%$ & 8 & $34,8 \%$ \\
$\mathbf{4 0}$ anos ou mais & 2 & $6,7 \%$ & 4 & $17,4 \%$ \\
\hline Total & 30 & $100,0 \%$ & 23 & $100,0 \%$ \\
\hline \hline Média & & 33,8 anos & 34,0 anos \\
\hline
\end{tabular}

Com relação à presença ou não de filhos em outras uniões, pode-se observar que vinte e sete mulheres $(90,0 \%)$ tem filhos em outras uniões enquanto três $(10,0 \%)$ teve filhos mas continua com o mesmo relacionamento. Dentre as 29 pacientes que informaram o número de filhos dessas uniões, duas mulheres têm um filho (6,9\%), nove mulheres tem dois filhos $(31,0 \%)$, dez mulheres tem três filhos $(34,5 \%)$ e cinco mulheres tem quatro filhos (17,2\%). Já dentre os parceiros, dos vinte e três que forneceram essa informação dezesseis não tinham filhos (69,6\%) enquanto sete já eram pais (30,4\%). Dos vinte e dois parceiros que informaram o número de filhos das uniões anteriores, apenas seis já tinham filhos, sendo que quatro possuem um filho (18,2\%), um possui dois filhos (4,5\%) e um possui quatro (4,5\%) (Tabela 2).

Tabela 2 - Número de Filhos da Mulher e do Parceiro em Relações Anteriores

\begin{tabular}{|c|c|c|c|c|}
\hline & \multicolumn{2}{|c|}{ Mulher } & \multicolumn{2}{|c|}{ Parceiro } \\
\hline & $n$ & $\%$ & $n$ & $\%$ \\
\hline $0^{*}$ & 3 & $10,3 \%$ & 16 & $72,7 \%$ \\
\hline 1 & 2 & $6,9 \%$ & 4 & $18,2 \%$ \\
\hline 2 & 9 & $31,0 \%$ & 1 & $4,5 \%$ \\
\hline 3 & 10 & $34,5 \%$ & 0 & $0 \%$ \\
\hline 4 & 5 & $17,2 \%$ & 1 & $4,5 \%$ \\
\hline Total & 29 & $100,0 \%$ & 22 & $100,0 \%$ \\
\hline
\end{tabular}

Com relação ao responsável pela criação desses filhos, dos dezoito prontuários que possuíam essa informação dez (55,6\%) afirmaram que elas próprias criam o filho, três compartilham a guarda com o ex-parceiro (16,7\%), duas relataram que os filhos são criados somente pelo ex-parceiro $(11,1 \%)$, duas disseram ter os filhos criados por parentes $(11,1 \%)$ e uma informou que os filhos faleceram (5,6\%). Dentre os cinco que informaram sobre o responsável pela criação todos disseram que os filhos são criados pela ex-parceira (Tabela 3). 


\section{REVISTA MÉDICA DO HC-UFPR}

Tabela 3 - Responsável pela Criação dos Filhos da Mulher e do Parceiro

\begin{tabular}{|c|c|c|c|c|}
\hline & \multicolumn{2}{|c|}{ Mulheres } & \multicolumn{2}{|c|}{ Parceiro } \\
\hline & $n$ & $\%$ & $\mathrm{n}$ & $\%$ \\
\hline Mulher & 10 & $55,6 \%$ & 0 & $0 \%$ \\
\hline Mulher e Ex-parceiro(a) & 3 & $16,7 \%$ & 0 & $0 \%$ \\
\hline Ex-Parceiro(a) & 2 & $11,1 \%$ & 5 & $100,0 \%$ \\
\hline Parentes & 2 & $11,1 \%$ & 0 & $0 \%$ \\
\hline Nascido Morto & 1 & $5,6 \%$ & 0 & $0 \%$ \\
\hline Total & 18 & $100,0 \%$ & 5 & $100,0 \%$ \\
\hline
\end{tabular}

Dentre as dezoito mulheres que possuíam a informação sobre o tempo da laqueadura tubária, uma mulher havia realizado a laqueadura entre 0 e 2 anos (5,6\%), duas entre 3 e 5 anos (11,1\%), seis entre 6 e 9 anos (33,3\%), cinco ente 10 e 14 anos (27,8\%) e quatro há mais de 15 anos (22,2\%) (Tabela 4).

Tabela 4 - Tempo da Laqueadura Tubária

\begin{tabular}{llc}
\hline & $\mathbf{n}$ & $\%$ \\
\hline $\mathbf{0}$ a $\mathbf{2}$ anos & 1 & $5,6 \%$ \\
$\mathbf{3}$ a anos & 2 & $11,1 \%$ \\
$\mathbf{6}$ a 9 anos & 6 & $33,3 \%$ \\
$\mathbf{1 0}$ a 14 anos & 5 & $27,8 \%$ \\
$\mathbf{1 5}$ anos ou mais & 4 & $22,2 \%$ \\
\hline Total & 18 & $\mathbf{1 0 0 , 0 \%}$ \\
\hline
\end{tabular}

Das vinte e quatro mulheres que informaram a idade no momento da laqueadura, cinco tinham menos de vinte anos $(20,8 \%)$, nove entre vinte e vinte e cinco anos $(37,5 \%)$, oito entre vinte e seis e trinta anos (33,3\%) e duas mais de trinta anos (8,3\%) (Tabela 5$)$.

Tabela 5 - Idade com que realizou laqueadura tubárea

\begin{tabular}{llc}
\hline & $\mathbf{n}$ & $\%$ \\
\hline Menos de 20 anos & 5 & $20,8 \%$ \\
$\mathbf{2 0}$ a 25 anos & 9 & $37,5 \%$ \\
$\mathbf{2 6}$ a $\mathbf{3 0}$ anos & 8 & $33,3 \%$ \\
Mais de $\mathbf{3 0}$ anos & 2 & $8,3 \%$ \\
\hline Total & $\mathbf{2 4}$ & $\mathbf{1 0 0 , 0 \%}$ \\
\hline
\end{tabular}

Analisando os vinte e seis prontuários podemos dizer que entre os motivos do desejo de reversão da laqueadura tubária, vinte e cinco mulheres $(96,1 \%)$ estão arrependidas e desejam mais filhos, vinte $(76,9 \%)$ tem um 


\section{ARTIGO ORIGINAL}

novo parceiro que deseja filhos, duas $(7,7 \%)$ desejam a reversão pelo falecimento dos filhos, uma $(3,8 \%)$ tem um novo parceiro e acha que um filho dele iria manter mais seguro o relacionamento, uma $(3,8 \%)$ quer mais um filho para ter companhia e uma (3,8\%) deseja reversão e não tem argumentos (Tabela 6).

Tabela 6 - Motivo do Desejo de Reversão da Laqueadura Tubária

\begin{tabular}{llc}
\hline & $\mathbf{n}$ & Percentual \\
\hline Arrependimento, quer mais filhos & 25 & $96,1 \%$ \\
\hline Tem um novo parceiro que deseja filhos & 20 & $76,9 \%$ \\
Falecimento de filhos & 2 & $7,7 \%$ \\
Tem um novo parceiro e acha que um filho iria manter mais seguro o & 1 & $3,8 \%$ \\
relacionamento & & $0,0 \%$ \\
Tem um novo parceiro e ele não está ciente da laqueadura & 0 & $3,8 \%$ \\
Quer mais um filho para ter companhia & 1 & $3,8 \%$ \\
\hline Deseja reversão mas não tem argumentos & 1 & $0,0 \%$ \\
\hline Por influência da televisão ou outros meios de comunicação & 0 & $0,0 \%$ \\
Não sabia que tinha sido esterilizada & 0 & $0,0 \%$ \\
\hline Outros & 0 & $\mathbf{1 9 2 , 1 \%}$ \\
\hline Total* & $\mathbf{2 6}$ & \\
\hline
\end{tabular}

Tabela 7 - Motivo do desejo de engravidar

\begin{tabular}{|c|c|c|}
\hline & $\mathrm{n}$ & Percentual \\
\hline Quer um filho ou mais um filho-desejo de ser mãe & 12 & $57,1 \%$ \\
\hline Tem um novo parceiro que deseja filhos & 15 & $71,4 \%$ \\
\hline Falecimento de filhos & 3 & $14,3 \%$ \\
\hline $\begin{array}{l}\text { Tem um novo parceiro e acha que um filho dele iria manter mais } \\
\text { seguro o relacionamento }\end{array}$ & 1 & $4,8 \%$ \\
\hline Quer mais um filho para ter companhia & 1 & $4,8 \%$ \\
\hline Parceiro ameaça separar-se caso não engravide & 0 & $0,0 \%$ \\
\hline O desejo de gestação é só da mulher & 0 & $0,0 \%$ \\
\hline O desejo de gestação é só do parceiro & 0 & $0,0 \%$ \\
\hline O desejo de gestação é por pressão de familiares & 0 & $0,0 \%$ \\
\hline Outros & 0 & $0,0 \%$ \\
\hline Total $^{*}$ & 21 & $152,4 \%$ \\
\hline
\end{tabular}

Dentre os vinte e um prontuários nos quais houve resposta sobre o motivo do desejo de engravidar, doze mulheres $(57,1 \%)$ querem um filho ou mais um filho pelo desejo de ser mãe, quinze mulheres $(71,4 \%)$ tem um novo parceiro que deseja filhos, três mulheres $(14,3 \%)$ desejam engravidar devido ao falecimento de filhos, uma mulher 
$(4,8 \%)$ tem um novo parceiro e acha que um filho dele iria manter mais seguro o relacionamento e uma mulher $(4,8 \%)$ quer mais um filho para ter companhia (Tabela 7).

Estudando os vinte e oito prontuários que continham o número de cesáreas realizadas pela mulher, $78,6 \%$ realizaram pelo menos uma cesárea. Dentre as dezenove mulheres que informaram sobre a última ocorrência da história obstétrica vemos que em $63,2 \%$ foi realizada cesárea, em 31,6\% parto normal e em $5,2 \%$ ocorreu aborto.

\section{DISCUSSÃO}

A média de idade das mulheres que consultaram desejosas da reversão da laqueadura tubária foi de 33,8 anos, sendo que 40,0\% das mulheres possuem de 34 a 39 anos, $36,7 \%$ de 30 a 34 anos. Esses dados estão de acordo com outros dois estudos publicados em 2005 e 2007 que encontrou a maioria das mulheres arrependidas com idade de inferior a 35 anos $(5,7,8)$. A média de idade também corresponde àquela de 33 anos e 3 meses encontrada em um estudo de 2007(8). Seus parceiros possuem de 21 a 47 anos, sendo que $34,8 \%$ tem de 34 a 39 anos, $21,8 \%$ entre 30 e 34 anos, $17,4 \% 40$ anos ou mais, $13 \%$ tem de 25 a 29 anos e $13 \%$ de 20 a 24 anos.e a de seus parceiros de 34,0 anos. Ao questionarmos a hipótese de essas mulheres estarem casadas com parceiros mais novos no momento da solicitação da reversão, observamos que a média de idade entre o casal é praticamente a mesma, não permitindo a sustentação dessa hipótese.

Observamos que dentre as mulheres, $89,7 \%$ possui pelo menos um filho de outras uniões, sendo que $82,8 \%$ pelo menos dois filhos. Observamos que dentre as pacientes por nós investigadas, 65,5\% tinham dois ou três filhos, valor próximo aos $72,5 \%$ encontrado em um estudo anterior(8). Já dentre os parceiros, chama a atenção o fato de que $72,7 \%$ não têm filhos de uniões prévias, correspondendo à maioria, assim como os $87,8 \%$ encontrados na literatura(8). Esses filhos, no caso das mulheres, são criados em $55,6 \%$ dos casos por elas próprias, outras 16,7\% compartilham a criação com o ex-parceiro. Já no caso dos parceiros atuais vemos que dentre os apenas 27,3\% que já tiveram filhos, todos estão sendo criados somente pela exparceira.

Os dados levantados com relação ao tempo decorrido da laqueadura nos mostram que $83,3 \%$ solicitou reversão após 6 anos. Em outro estudo de 2007 mostrou que apenas $21,4 \%$ das mulheres levaram mais de 6 anos para se arrepender(8). Por outro lado, nossos dados assemelham-se com os encontrados em 1996 em Campinas - SP, onde 72,2\% das pacientes solicitam reversão após 6 anos de esterilização(4).
Também identificamos que $20,8 \%$ das pacientes foram esterilizadas com menos de 20 anos. Outras 37,5\% realizaram a laqueadura com idade entre 20 e 25 anos, - que chama a atenção ao analisarmos a recomendação da lei 9263/1996 que refere que a equipe multidisciplinar de regulação da fertilidade deve desencorajar as esterilizações precoces(6).

Com relação à idade de realização da laqueadura, 58,3\% das pacientes desejosas de reversão foram esterilizadas com menos de 25 anos. Essa informação está de acordo com dados da literatura que indicam idade menor de 25 anos como fator de risco para solicitar a reversão da laqueadura(4).

Estudando os motivos que levaram essas mulheres a solicitar a reversão notamos que $96,1 \%$ das pacientes se arrependeram de ter feito a laqueadura e desejam mais filhos, 76,9\% delas têm um novo parceiro que deseja filhos, corroborando com o fato de que dentre os parceiros, $72,7 \%$ não têm filhos de outras uniões. O desejo de reversão devido ao falecimento de filhos foi apontado por $7,7 \%$ das pacientes. A idéia de que um filho traria mais estabilidade em um novo relacionamento foi levantada por $3,8 \%$ das mulheres assim como o desejo de companhia ou o simples desejo de reversão sem argumentos. Esses dados vão ao encontro daqueles presentes na literatura que demonstram a presença de um novo parceiro como causa importante no desejo de reversão e o falecimento de filhos como motivo para uma pequena parcela das mulheres $(1,8)$.

Estudando a possível via de acesso para a laqueadura nessas pacientes observamos que $78,6 \%$ haviam realizado pelo menos uma cesariana. Esse valor se mostrou similar àqueles encontrados pela literatura ao indicar que $80 \%$ das pacientes esterilizadas tiveram esse procedimento realizado durante uma cesárea(7). Muitos prontuários não contem essa informação, uma vez que as pacientes podem ter sido esterilizadas em outros serviços médicos e não na Maternidade do Hospital de Clínicas da Universidade Federal do Paraná. Em 63,2\% das pacientes o último evento da história obstétrica foi uma cesárea, em 31,6\% houve parto normal e em 5,2\% ocorreu aborto.

O desejo de engravidar se opõe ao motivo do desejo de reversão por não se preocupar tanto em compreender o motivo do arrependimento, mas sim o por que de um filho ou mais um filho nesse momento da vida. Ao explorarmos esse item vemos que, ao contrário do motivo do desejo de reversão, a causa mais apontada, $71,4 \%$ das mulheres, foi a presença de um novo parceiro que deseja filhos, seguido pelo desejo de ser mãe apontado por $57,1 \%$ das pacientes. Esse fato, aponta mais uma vez para a presença de um novo relacionamento como um item fundamental no desejo de ser mãe novamente implicando em um arrependimento da esterilização(1,8). Além disso, $14,3 \%$ das pacientes referiram desejar engravidar 


\section{ARTIGO ORIGINAL}

devido ao falecimento de filhos; $4,8 \%$ acham que um filho traria maior estabilidade ao relacionamento e outros $4,8 \%$ desejam um filho para ter companhia.

Os dados por nós encontrados nesse estudo assemelham-se em muitos pontos com aqueles presentes na literatura e reforçam os riscos de se recorrer à laqueadura tubária como método contraceptivo. Apesar de sua alta eficácia, na sociedade atual em que as separações e novas uniões entre casais estão se tornando cada vez mais comuns, torna-se difícil para cada mulher prever o seu futuro reprodutivo. Além disso, podemos ressaltar a importância da lei 9263/1996 que tem por objetivo evitar esterilizações precoces e em pacientes que ainda não possuem a prole constituída e garante tempo para uma tomada de decisão mais segura evitando a realização de um procedimento definitivo em um momento de impulso. Vimos também que não só a presença de um novo parceiro, mas o simples reaparecimento do desejo de ser mãe inerente à mulher pode ser uma das principais causas do arrependimento.

Considerando nossa experiência e as publicações de outros serviços, somos da opinião que devem ser evitadas as laqueaduras em mulheres jovens com até trinta anos de idade em especial entre as mulheres com até 25 anos de idade. Métodos de contracepção tão eficazes quanto à laqueadura, de longa duração e aplicação única ou poucas aplicações como o dispositivo intra-uterino, injetáveis e implantes podem e devem ser disponibilizados a essa paciente, evitando desse modo, arrependimentos futuros e infelicidades evitáveis, exceção deve ser feita no caso de mulheres de alto risco para uma nova gravidez como os portadores de certas doenças e várias cesáreas, quando a indicação é médica

\section{CONCLUSÕES}

As mulheres que solicitaram reversão de laqueadura tubária têm idade média de aproximadamente 34 anos e apresentam filhos de uniões anteriores.

A grande maioria das pacientes foi submetida a laqueadura tubária há mais de 6 anos, em sua maioria com idade de 20 a 30 anos. Em cerca de um quinto dessas pacientes a esterilização foi realizada quando as pacientes tinham menos de 20 anos.

As consultas pedindo reversão da laqueadura ocorrem em média quando as mulheres chegam aos 34 anos de idade e sua esterilização ocorreu com idade média de 30 anos.

Os motivos referidos pelas mulheres para desejar a reversão é estarem arrependidas e desejarem mais filhos e cerca de três quartos delas tinham um novo parceiro que desejava filhos. O motivo de desejar engravidar na maioria das vezes foi por ter um novo parceiro que desejava filhos.

Em quase dois terços das mulheres, o último procedimento da história obstétrica foi uma cesárea.

\section{REFERÊNCIAS BIBLIOGRÁFICAS}

1. MACHADO, Katia Maria de Melo; LUDERMIR, Ana Bernarda and COSTA, Aurélio Molina da. Changes in family structure and regret following tubal sterilization. Cad. Saúde Pública [online]. 2005 , v. 21 , n. 6 , pp. $1768-1777$.

2. BRASIL. Ministério da Saúde, Centro Brasileiro de Análise e Planejamento. Pesquisa Nacional de Demografia e Saúde da Criança e da Mulher - PNDS 2006 : dimensões do processo reprodutivo e da saúde da criança/ Ministério da Saúde, 2009.

3. BEREK, Jonathan S. Berek \& Novak: Tratado de Ginecologia, 14a edição. Rio de Janeiro: Guanabara Koogan, 2008.

4. HARDY, Ellen. et al. Risk factors for tubal sterilization regret, before surgery. Contraception, 1996. v.54, pp. 159-162.

e mulheres laqueadas arrependidas em serviço público de esterilidade conjugal. Rev. Bras. Ginecol. Obstet. [online]. 2001, v. 23, n. 2 , pp. $69-73$

5. BRASIL. Constituição (1998). Constituição da República Federativa do Brasil, DF : Senado, 1988.

6. CARVALHO, Luiz Eduardo Campos de. et al. Número ideal de filhos e arrependimento pós-laqueadura. Rev. Assoc. Med. Bras. [online]. 2006, v. 52, n. 5, pp. 293-297.

7. CUNHA, Antônio Carlos Rodrigues da; WANDERLEY, Miriam da Silva; GARRAFA, Volnei. Fatores associados ao futuro reprodutivo de mulheres desejosas de gestação após ligadura tubária. Rev. Bras. Ginecol. Obstet. 2007; 29(5):230-4 